\title{
Effects of orally inhaled budesonide in seasonal allergic rhinitis
}

\author{
L. Greiff*, M. Andersson*, C. Svensson*, M. Linden**, P. Wollmer+, \\ R. Brattsand**, C.G.A. Persson**,++
}

Effects of orally inhaled budesonide in seasonal allergic rhinitis. L. Greiff, M. Andersson, C. Svensson, M. Linden, P. Wollmer, R. Brattsand, C.G.A. Persson. CERS Journals Ltd 1998.

ABSTRACT: It has previously been demonstrated that topical nasal treatment with glucocorticosteroids has significant effects on the bronchial airways. Less is known about effects on nasal disease by topical bronchial treatment with these drugs.

The present study examined effects on nasal allergic disease of inhaled budesonide (avoiding nasal deposition of the drug). Patients with seasonal allergic rhinitis, but without asthma, were thus given inhalations of budesonide $(600 \mu \mathrm{g}$ b.i.d.) or placebo. The aim of the design was to allow the study of eosinophilic airway disease in a part of the airway other than the directly treated locus.

Moderate to high birch pollen levels were recorded during the study season, and nasal symptoms were significantly increased in both treatment groups, although they were milder in patients receiving budesonide than in the placebo group $(\mathbf{p}<0.05)$. Nasal brush eosinophils and nasal lavage fluid levels of eosinophil cationic protein as well as blood eosinophils were increased during the season $(p<0.05)$, but these increases were prevented by the inhaled budesonide. Nasal lavage fluid levels of $\alpha_{2}$-macroglobulin were particularly elevated in the placebo group but did not differ between patients receiving placebo and budesonide. Budesonide prevented the seasonal development of increased bronchoconstrictor responses to methacholine challenge $(\mathbf{p}<0.05)$.

In conclusion, budesonide reduced the seasonal eosinophilia both in the circulation and in the nose along with an attenuation of seasonal nasal symptoms. Hence, at a daily dose of $600 \mu \mathrm{g}$ b.i.d., known to cause no, or minimal, adverse effects, inhaled budesonide produces clinically significant anti-inflammatory effects in the entire airways, including the nasal mucosa, which is not exposed topically to the drug. We suggest that nasal and systemic anti-eosinophil actions are produced at commonly employed dose levels of orally inhaled budesonide.

Eur Respir J 1998; 11: 1268-1273.
*Dept of Otorhinolaryngology, Head \& Neck Surgery, University Hospital, Lund, Sweden. **Dept of Preclinical Research \& Development, Astra Draco, Lund, Sweden. +Dept of Clinical Physiology, University Hospital, Malmö, Sweden.++Dept of Clinical Pharmacology, University Hospital, Lund Sweden.

Correspondence: L. Greiff

Dept of Otorhinolaryngology, Head \& Neck Surgery

University Hospital

S-221 85 Lund

Sweden

Fax: 46462110968

Keywords: Allergy

bronchial

eosinophil cationic protein

glucocorticosteroids

inflammation

nasal

Received: September 91997

Accepted after revision February 151998

The present study was supported by the Swedish Medical Research Council (projects 8308 and 10841), the Varrdal Foundation, the Medical Faculty of Lund University, and the Swedish Association against Asthma and Allergy.
Topical airway glucocorticosteroids are effective anti-inflammatory drugs that may lack clinically relevant systemic adverse reactions. This treatment, which is increasingly becoming a first-line treatment for asthma and rhinitis, is thought to reflect topical airway drug action [1]. However, a contribution from systemic anti-inflammatory action cannot be excluded. It is well described that soon after inhalation a significant portion of the dose that has been deposited on the airway and lung mucosal and alveolar surfaces will be absorbed into the blood [1]. It is also clear from studies of human leukocytes in vitro that low glucocorticosteroid concentrations, equivalent to the peak plasma concentrations reached following inhalation, may exert anti-inflammatory effects [2]. The possibility of anti-inflammatory efficacy of systemically absorbed airway glucocorticosteroids is also supported by observations on bronchial airway effects of topical nasal glucocorticosteroids in patients with seasonal airway disease [3-5]. Altern-atively, since the entire airway mucosa may be abnormal in asthma [6,7], effective treatment of part of that abnormality (e.g. in the nose) may somehow also have a beneficial influence on the bronchi (see later)

In the present study, we have examined whether budesonide inhaled orally exerts anti-inflammatory effects in the nose. We have administered budesonide to relatively healthy bronchi by selecting patients that usually develop seasonal allergic rhinitis but not asthma during a natural birch pollen season. We have examined nasal symptoms, indices of exudative and eosinophilic nasal inflammation, blood eosinophils, bronchial symptoms, and bronchial response to methacholine. All the selected variables may be abnormal in both allergic asthma and allergic rhinitis, and most of them show glucocorticosteroid sensitivity $[1,8$, 9].

\section{Material and methods}

\section{Study design}

A placebo-controlled, parallel group, double-blind design was used in this study. Patients with allergic rhini- 
tis were treated with either placebo or inhaled budesonide (600 $\mu \mathrm{g}$ b.i.d.) during the birch pollen season of 1995. The inhalation was given so as to avoid direct exposure of the nasal passages. Effects of the treatment were examined on: nasal symptoms of allergic rhinitis; morning nasal lavage fluid levels of $\alpha_{2}$-macroglobulin and eosinophil cationic protein $(\mathrm{ECP})$; number of eosinophils in nasal brushings; number of blood eosinophils; bronchial symptoms and bronchial responsiveness to methacholine challenges. The morning nasal lavages were carried out both well before the pollen season and treatment and during the pollen season and treatment (study weeks 1-7). The nasal brushings, blood sampling, and bronchial challenges were carried out once before the pollen season and treatment period and once again during the pollen season and treatment period (approximately study week 6).

\section{Patients}

The patients were recruited from the Department of Otorhinolaryngology, Head \& Neck Surgery, University Hospital, Lund, Sweden. Forty patients with seasonal allergic rhinitis were included. The inclusion criteria were Š18 yrs of age and a history of strictly seasonal allergic rhinitis with a positive skin prick test to birch pollen allergen. The exclusion criteria were a history of chest symptoms during the birch pollen season, history of chronic bronchial disease including asthma, history of chronic nasal disease other than seasonal allergic rhinitis, positive skin prick tests to perennial allergens, drug treatment, and smoking.

\section{Treatment}

Budesonide $(600 \mu \mathrm{g}$ b.i.d.) and placebo (powder) were administered using Turbuhaler®-devices. The patients were instructed to hold their breath for $10 \mathrm{~s}$ after drug administration and then to take five breaths through the mouth before breathing normally again. During inhalation and during the following breaths, nose-clips were used. This practice was to avoid any nasal exposure to the inhaled drug. The patients were further instructed to rinse their mouth after each administration. The treatment started 2 weeks prior to the expected start of the birch pollen season and continued throughout the entire pollen season.

The patients were given allocation numbers. The order of treatment proceeded according to a randomization scheme of the allocation numbers (prepared in blocks). The treatment was randomized so that 20 of the patients were on active drug. Blindness was maintained by the identical appearance of active and placebo preparations. No medication, other than the study drug and rescue medication, was allowed during the study. Any previous nasal therapy was discontinued for at least 4 weeks before entry into the study. The rescue medication was oxymethazoline nasal spray (Nezerilß, Astra) and levocabastin eye-drops and nasal spray (Livostin ${ }^{\circledR}$, Janssen-Cilag).

\section{Nasal and bronchial symptoms}

Rhinorrhea, blockage, and sneezes were scored daily by the subjects on a four-point scale: 0 : none; 1 : mild; 2 : moderate; and 3: severe symptoms. Similarly, the degree of chest congestion was scored daily by the subjects on a four-point scale.

\section{Nasal mucosal output of $\alpha_{2}$-macroglobulin and ECP}

Nasal morning lavages were performed at the laboratory before and once a week during the birch pollen season using a nasal pool device [10] containing $15 \mathrm{~mL}$ of isotonic saline. The lavage fluids were kept in the nasal cavity for $10 \mathrm{~min}$. The recovered lavage fluid was centrifuged $\left(105 \times \mathrm{g}, 10 \mathrm{~min}, 4^{\circ} \mathrm{C}\right)$, and aliquots were prepared from the supernatants and frozen $\left(-20^{\circ} \mathrm{C}\right)$ for later analysis. The lavage fluid level of $\alpha_{2}$-macroglobulin was examined as an index of mucosal exudation of plasma. Furthermore, the lavage fluid levels of ECP were examined.

\section{Number of nasal and blood eosinophils}

Nasal brush samples were obtained before, and during, the pollen season (study week 5), and the percentage of eosinophils was examined. Blood samples were similarly obtained before, and during, the pollen season, and the numbers of eosinophils were examined. Blood samples and nasal brushings were collected on the same day. For blood eosinophils, $10 \mathrm{~mL}$ of blood were collected into tubes containing heparin.

\section{Bronchial responsiveness to methacholine-challenge}

Before the methacholine challenge series, a baseline forced expiratory volume in one second (FEV1) was recorded, i.e., the highest FEV1 recorded of three consecutive tests, using an electronic spirometer (Vitalograph-Compact II, Buckingham, UK). Thereafter, the subjects inhaled increasing doses of methacholine starting with an initial dose of $2 \mu \mathrm{g}$. FEV 1 was recorded 3 min after each challenge, and the challenges were continued until a cumulative dose of $3160 \mu \mathrm{g}$ had been given or until a $20 \%$ decrease in FEV1 from baseline was achieved [11]. The individual bronchial response monitored as FEV1 (\%) was assessed at the highest dose level of methacholine that could be given at both challenge occasions.

\section{Analysis}

The nasal lavage fluid levels of $\alpha_{2}$-macroglobulin were measured using a radioimmunoassay (RIA) sensitive to 8 $\mathrm{ng} \cdot \mathrm{mL}^{-1}$. Rabbit anti-human $\alpha_{2}$-macroglobulin (Dakopatts, Copenhagen, Denmark) was used as antiserum, and human serum (Behringwerke Diagnostica, Marburg, Germany) was used as the standard. Human $\alpha_{2}$-macroglobulin (Cappel-Organon Teknika, Turnhout, Belgium) was iodinated using the lactoperoxidase method. Tracer and standard or sample was mixed with antiserum before adding goat anti-rabbit antiserum (Astra Draco, Lund, Sweden). The bound fraction was measured using a gamma counter (Pharmacia, Uppsala, Sweden). The intra- and inter-assay coefficients of variation were between $3.8-6.0 \%$ and 3.1$7.2 \%$, respectively. The nasal lavage fluid levels of ECP were measured using an enzyme-linked immunosorbent assay (ELISA) (Pharmacia, Sweden). 


\section{Statistics}

Firstly, differences in nasal, blood, and bronchial indices between observations before and during the pollen season were examined with paired tests within each treatment group using the Friedman test and, if statistical significance emerged, the Wilcoxon signed rank test (WSR test). Secondly, differences between placebo and bronchial budesonide treatments were examined in an unpaired test using the Mann-Whitney U-test (MWU test). Data are presented as means \pm SEM.

\section{Results}

Forty patients were enrolled into the study. Five patients failed to follow the protocol and were excluded. Of the remaining 35 patients, 17 received placebo and 18 received bronchial budesonide. The birch-pollen counts, recorded about $20 \mathrm{~km}$ from the study area, showed moderate to high levels (fig. 1). Nasal symptoms recorded during the study period accordingly exhibited a significant increase from baseline in patients receiving placebo from study weeks 3-7 and in patients receiving bronchial budesonide from study week 4 onwards (fig. 2, table 1). In patients receiving bronchial budesonide, nasal symptoms were reduced compared with placebo during study weeks 5 and 6 (fig. 2, table 1).

Nasal lavage fluid levels of $\alpha_{2}$-macroglobulin were significantly elevated compared to the baseline in patients receiving placebo (Friedman test $\mathrm{p}<0.05$, WSR test $\mathrm{p}<$ 0.05 study weeks 2 and $5-7 ; \mathrm{p}<0.01$ study week 4 ) (table $2)$. This increase was not observed in patients receiving bronchial budesonide (Friedman test $\mathrm{p}=0.15$ ). However, a difference in nasal lavage fluid levels of $\alpha_{2}$-macroglobulin between patients receiving placebo and bronchial budesonide was suggested in study week 7 (MWU test $\mathrm{p}=0.05$ ), but otherwise there were no significant differences in lavage fluid levels of $\alpha_{2}$-macroglobulin (MWU test $p>0.05$ ).

Nasal lavage fluid levels of ECP were significantly elevated in patients receiving placebo (Friedman test $p<0.01$, WSR $p<0.05$ study week $5 ; \mathrm{p}<0.01$ study weeks 4 and 6 ) (fig. 3). This increase was not observed in patients receiv-

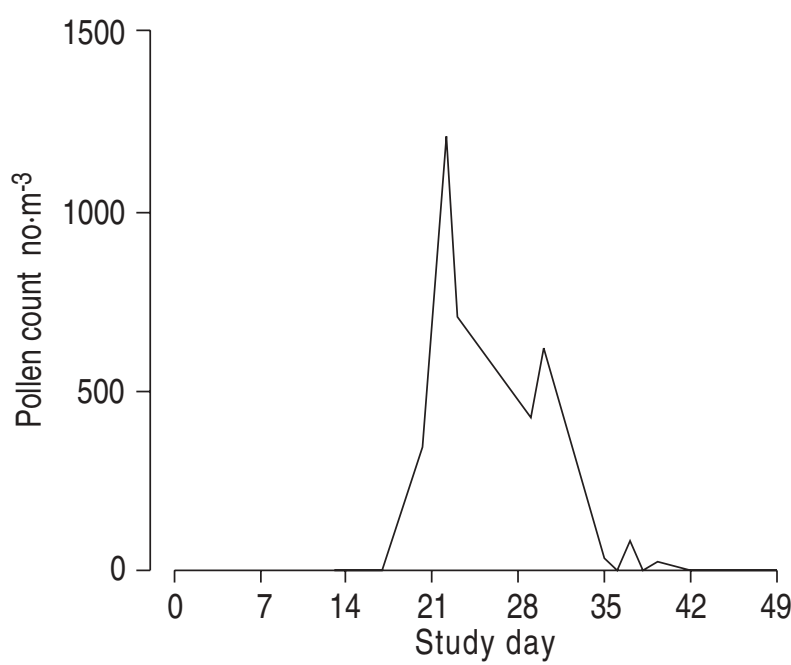

Fig. 1. - Pollen counts during the 7 week study period. The counts demonstrate a moderate $3-4$ week birch pollen season ing bronchial budesonide (Friedman-test $\mathrm{p}=0.32$ ). A statistical difference in nasal lavage fluid levels of ECP between patients receiving placebo and bronchial budesonide was observed in study week 5 (MWU test $\mathrm{p}<0.05$ ).

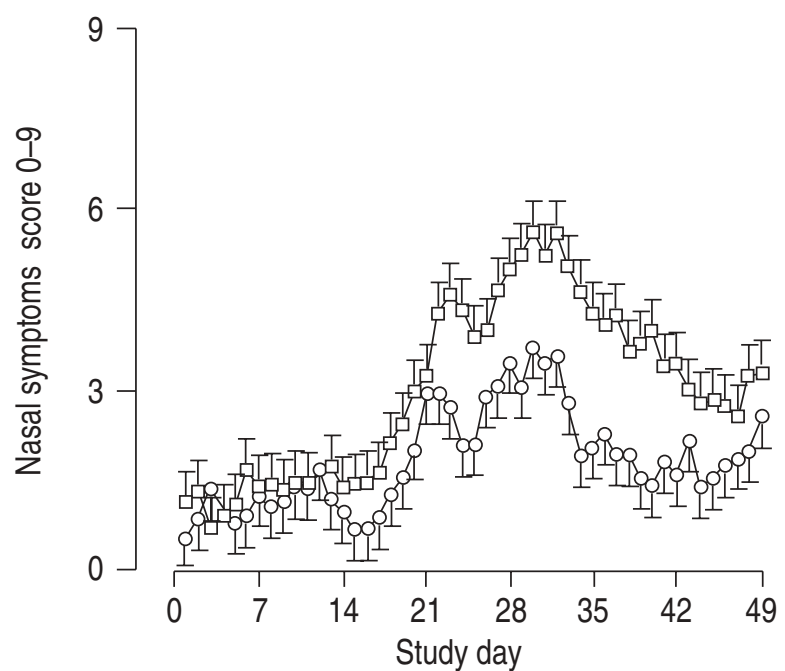

Fig. 2. - Nasal symptoms scored during the study period. The scoresdemonstrate a significant increase in nasal symptoms in patients receiving either inhaled placebo and budesonide. However, the scores were significantly lower in patients receiving budesonide. (See table 1 for significance levels within and between groups.) $-\square-$ : placebo; $-\mathrm{O}-$ : budesonide.

Table 1. - Nasal symptoms (score 0-63) per week during the 7 week study period, compared with scores obtained during study week 1 within each group (WSR test) and compared between placebo and budesonide (MWU test)

\begin{tabular}{cccccc}
\hline \multirow{2}{*}{$\begin{array}{l}\text { Study } \\
\text { week }\end{array}$} & \multicolumn{5}{c}{ Symptom score } \\
\cline { 2 - 6 } & & $\begin{array}{l}\text { p-value } \\
\text { (WSR) }\end{array}$ & Budesonide & $\begin{array}{c}\text { p-value } \\
\text { (WSR) }\end{array}$ & $\begin{array}{c}\text { p-value } \\
\text { (MWU) }\end{array}$ \\
\hline 1 & $8.8 \pm 1.4$ & & $7.1 \pm 1.8$ & & NS \\
2 & $10.6 \pm 2.0$ & NS & $9.5 \pm 2.6$ & NS & NS \\
3 & $15.5 \pm 3.0$ & $<0.05$ & $8.3 \pm 1.9$ & NS & NS \\
4 & $30.7 \pm 4.6$ & $<0.01$ & $18.8 \pm 3.3$ & $<0.01$ & NS \\
5 & $36.3 \pm 4.9$ & $<0.001$ & $22.0 \pm 4.0$ & $<0.01$ & $<0.05$ \\
6 & $26.5 \pm 3.5$ & $<0.001$ & $13.1 \pm 3.2$ & $<0.05$ & $<0.01$ \\
7 & $16.7 \pm 2.5$ & $<0.01$ & $12.5 \pm 3.1$ & $<0.05$ & NS \\
\hline
\end{tabular}

ss: nonsignificant; WSR: Wilcoxon signed rank. MWU: MannWhitney U test.

Table 2. - Nasal lavage fluid levels of $\alpha_{2}$-macroglobulin $\left(\mu \mathrm{g} \cdot \mathrm{mL}^{-1}\right)$ during the study period, compared with levels obtained during tests in March (before the pollen season) within each group (WSR test) and compared between placebo and budesonide (MWU test)

\begin{tabular}{cccccc}
\hline \multirow{2}{*}{$\begin{array}{c}\text { Study } \\
\text { week }\end{array}$} & Placebo & $\begin{array}{c}\text { p-value } \\
\text { (WSR) }\end{array}$ & Budesonide & $\begin{array}{l}\text { p-value } \\
\text { (WSR) }\end{array}$ & $\begin{array}{c}\text { p-value } \\
\text { (MWU) }\end{array}$ \\
\cline { 2 - 6 } March & $0.7 \pm 0.2$ & & $0.6 \pm 0.1$ & & NS \\
1 & $2.4 \pm 1.1$ & NS & $3.5 \pm 1.6$ & $<0.01$ & NS \\
2 & $2.0 \pm 0.8$ & $<0.05$ & $2.5 \pm 0.8$ & NS & NS \\
3 & $1.0 \pm 0.3$ & NS & $12.1 \pm 0.4$ & NS & NS \\
4 & $2.0 \pm 0.5$ & $<0.01$ & $1.3 \pm 0.5$ & NS & NS \\
5 & $2.4 \pm 1.0$ & $<0.05$ & $1.5 \pm 0.7$ & NS & NS \\
6 & $2.1 \pm 0.5$ & $<0.05$ & $1.7 \pm 0.6$ & $<0.05$ & NS \\
7 & $1.1 \pm 0.2$ & $<0.05$ & $0.7 \pm 0.1$ & NS & NS
\end{tabular}

NS: nonsignificant; WSR: Wilcoxon signed rank test. MWU: Mann-Whitney U test. 


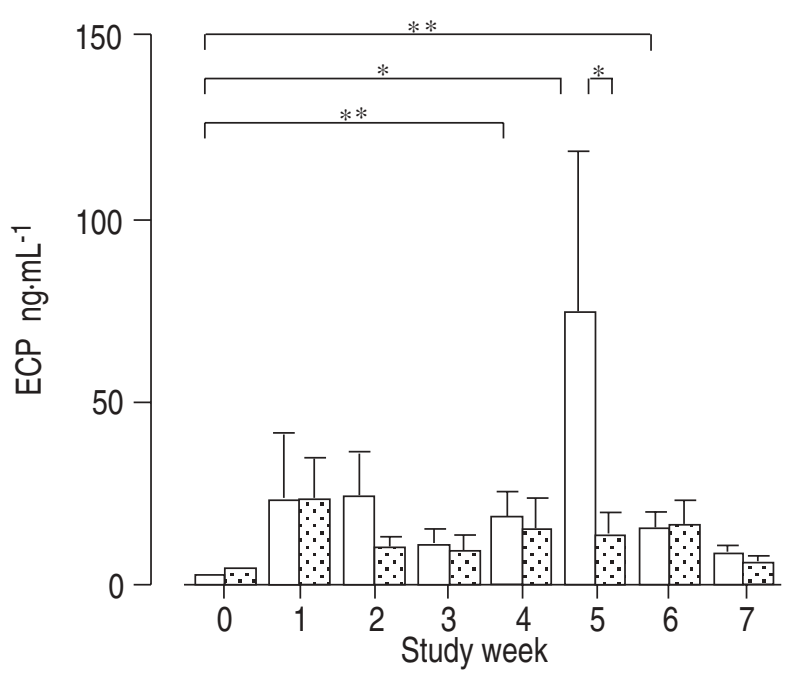

Fig. 3. - Nasal lavage fluid levels of eosinophil cationic protein recorded before and once a week during the study period. The levels were significantly elevated in study weeks $4-6$ in patients receiving inhaled placebo $(* \mathrm{p}<0.05, * * \mathrm{p}<0.01)$. The levels were significantly lower in patients receiving budesonide in study week $5\left({ }^{*} \mathrm{p}<0.05\right) . \square$ : placebo; $\because \because$ : budesonide.

The percentage of nasal eosinophils was increased late into the season (study week 5 ) in patients receiving placebo treatment (WSR test $\mathrm{p}<0.01$ ) (fig. 4). This increase was not observed in patients receiving bronchial budesonide (WSR test $\mathrm{p}=1.0$ ). Furthermore, a statistical difference in the percentage of nasal eosinophils between patients receiving placebo and bronchial budesonide was observed during the season (MWU test $\mathrm{p}<0.05$ ).

The percentage of blood eosinophils increased late into the season (study week 5) in patients receiving placebo treatment (WSR test $\mathrm{p}<0.01$ ) (fig. 5). This increase was not observed in the budesonide group (WSR test $\mathrm{p}=0.7$ ) (fig. 5). Furthermore, a statistical difference in the per-

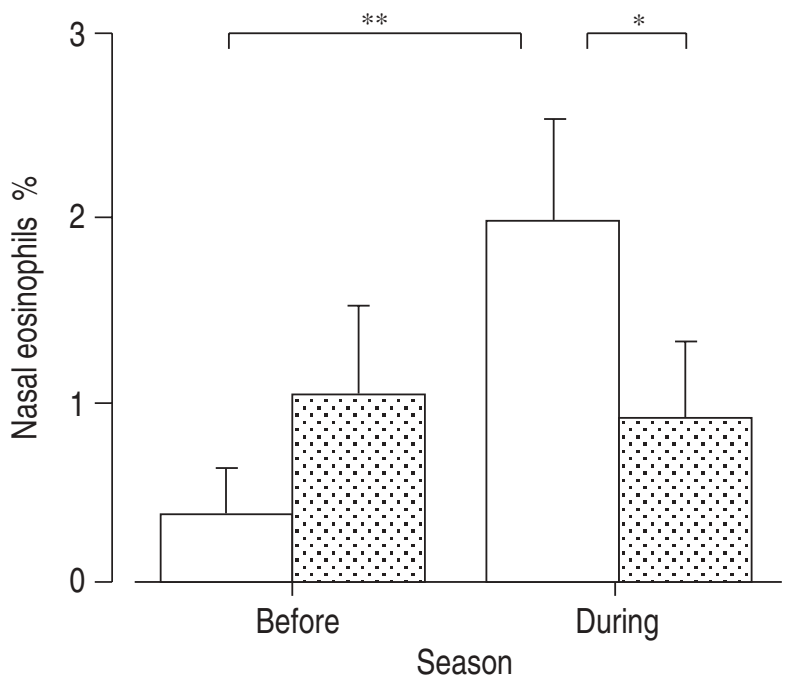

Fig. 4. - Percentage of nasal brush eosinophils. The percentage of eosinophils was increased during the season in patients receiving inhaled placebo $(* * \mathrm{p}<0.01)$. This increase was not seen in patients receiving budesonide. Furthermore, the percentage of nasal brush eosinophils was significantly lower during the season in patients receiving budesonide than in those receiving placebo $(* \mathrm{p}<0.05) . \square$ : placebo; $\square$ - $\square$ : budesonide.

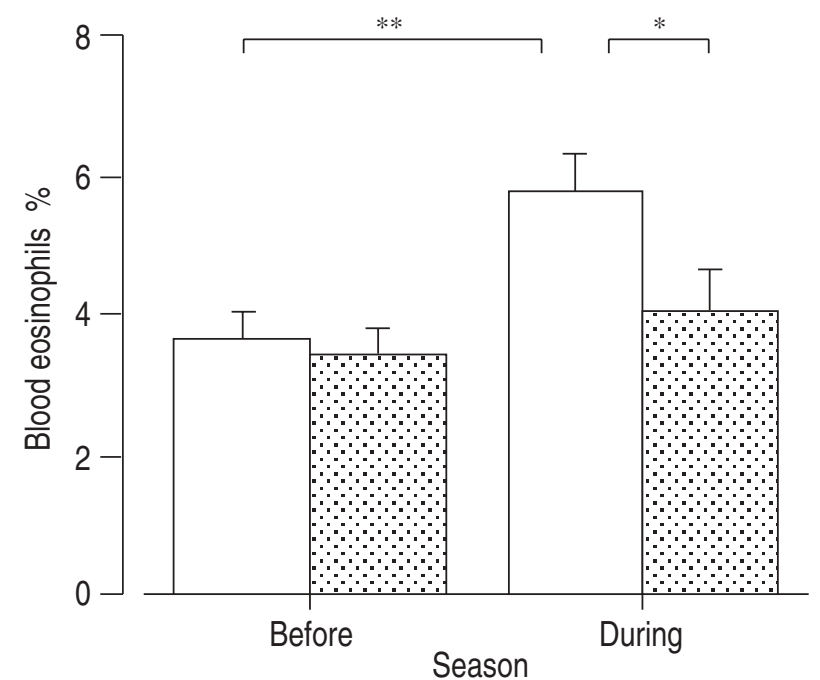

Fig. 5. - Numbers of blood eosinophils before and during the pollen season. The percentage of eosinophils was increased during the season in patients receiving inhaled placebo $(* * \mathrm{p}<0.01)$. This increase was not seen in patients receiving budesonide. Furthermore, the percentage of blood eosinophils was significantly lower during the season in patients receiving budesonide than in those receiving placebo $\left({ }^{*} \mathrm{p}<0.05\right)$. $\square$ : placebo; $\because \because$ : budesonide.

centage of blood eosinophils between patients receiving placebo and bronchial budesonide was observed during the season (MWU test $\mathrm{p}<0.05$ ).

Bronchial symptoms recorded during the study period showed a significant increase from the baseline in patients who received placebo in weeks 4-7 and in patients who received bronchial budesonide in study week 4 (table 3 ). In patients receiving budesonide, a reduction in bronchial symptoms was observed late into the pollen season (study week 6) compared with the placebo.

Bronchial methacholine challenges were performed to the cumulative dose of $3,160 \mu \mathrm{g}$ in all patients before and late into the birch pollen season. The reduction in FEV1 recorded after the completed cumulative dose was significantly greater during the pollen season in patients receiving placebo (WSR test $\mathrm{p}<0.01$ ) (fig. 6). In patients receiving bronchial budesonide, the reduction in FEV1 after challenge was similar before, and during, the birch pollen season (WSR test $\mathrm{p}=1.0$ ).

Table 3. - Bronchial symptoms (score 0-21) per week during the 7 week study period, compared with scores obtained during study week 1 within each group (WSR test) and compared between placebo and budesonide (MWU test)

\begin{tabular}{cccccc}
\hline \multirow{2}{*}{$\begin{array}{c}\text { Study } \\
\text { week }\end{array}$} & \multicolumn{5}{c}{ Symptom score } \\
\cline { 2 - 6 } & Placebo & $\begin{array}{c}\text { p-value } \\
\text { (WSR) }\end{array}$ & Budesonide & $\begin{array}{c}\text { p-value } \\
\text { (WSR) }\end{array}$ & $\begin{array}{c}\text { p-value } \\
\text { (MWU) }\end{array}$ \\
\hline 1 & $0.8 \pm 0.4$ & & $1.4 \pm 1.1$ & & NS \\
2 & $1.1 \pm 0.5$ & NS & $0.4 \pm 0.2$ & NS & NS \\
3 & $1.7 \pm 0.7$ & NS & $1.3 \pm 0.9$ & NS & NS \\
4 & $7.6 \pm 1.3$ & $<0.01$ & $5.6 \pm 1.6$ & $<0.05$ & NS \\
5 & $4.9 \pm 1.3$ & $<0.05$ & $3.3 \pm 1.5$ & NS & NS \\
6 & $6.2 \pm 1.8$ & $<0.01$ & $2.3 \pm 1.2$ & NS & $<0.05$ \\
7 & $5.2 \pm 1.6$ & $<0.01$ & $4.7 \pm 2.2$ & NS & NS \\
\hline
\end{tabular}

Ns: nonsignificant; WSR: Wilcoxon signed rank test. MWU: Mann-Whitney U test. 


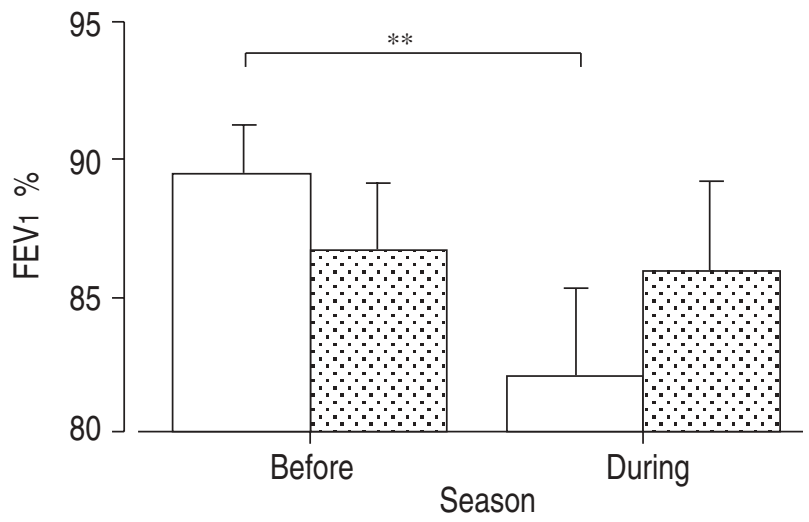

Fig. 6. - Forced expiratory volume in one second (FEV1) after bronchial challenge with methacholine before and during the pollen season in patients receiving inhaled placebo and budesonide. The individual bronchial response was assessed at the highest dose level of methacholine that could be given at both challenge occasions i.e. $3160 \mu \mathrm{g}$ in all subjects. In patients receiving placebo, the reduction in FEV1 was significantly greater during the season than before the season $(* *$ $\mathrm{p}<0.01)$. This augmented reduction was not observed in patients receiving budesonide. $\square$ : placebo; $\because \cdot$ : budesonide.

\section{Discussion}

The present study, involving patients with allergic rhinitis, has demonstrated that bronchial budesonide (inhaled budesonide $600 \mu \mathrm{g}$ b.i.d.) inhibits the seasonal increase in blood and nasal eosinophils, and nasal lavage fluid levels of ECP. In addition, nasal symptoms were reduced. These findings are of interest with regard to the present treatment of inflammatory airway diseases and, perhaps, with regard to what may be ideal properties of airway glucocorticosteroid drugs.

Particular care was taken to avoid nasal deposition of inhaled budesonide in this study. Nose clips were employed and the patients were instructed (and initially supervised) to breathe through the mouth for at least $10 \mathrm{~s}$ after each administration. Accordingly, we consider it unlikely that the present effects of budesonide are due to direct nasal deposition of the glucocorticosteroid. The patients had no history of asthma but, as is common in patients with seasonal allergic rhinitis [3-5], those receiving placebo developed a mild airway condition with increased responses to inhalational methacholine challenge during the pollen season. The budesonide treatment prevented the increased response to methacholine, indicating that the glucocorticosteroid was topically effective in the bronchi of the present patients. These data agree with the notion that patients with allergic rhinitis develop a mild inflammatory reaction in their bronchi when they are naturally exposed to the appropriate allergen.

Whereas the selected dose of inhaled budesonide $(600$ $\mu \mathrm{g}$ b.i.d.) is considered not to provoke any clinically important adverse reactions in adults [1], an impaired hypothalamic-pituitary-adrenal (HPA)-axis and/or reduced osteocalcin levels can be demonstrated $[1,12,13]$. Such biochemical evidence of systemic activity of similar or greater magnitude has been demonstrated also for other glucocorticosteroids including fluticasone propionate and beclomethasone dipropionate $[1,12,14]$. A certain systemic activity of inhaled glucocorticosteroids that are inactivated in the liver is not surprising because the lungdeposited fraction of all antiasthma glucocorticosteroids is bioavailable [15]. If the systemic and nasal treatment effects in this study are due to pulmonary absorption of budesonide, these data suggest that inhibition of allergic eosinophilia is extremely sensitive to systemic pulses of glucocorticosteroid drugs. This possibility may be specifically tested through rather elaborate studies involving repeated daily intravenous pulses of budesonide closely mimicking the plasma concentration curves that are produced by the inhaled glucocorticosteroid. Previously, T00G00D et al. [16] have demonstrated that an oral daily dose of budesonide $(1.4 \mathrm{mg})$ was ineffective in asthma compared to the inhalation of $400 \mu \mathrm{g}$ of budesonide.

It is possible that the efficacy of inhaled glucocorticosteroids may depend on a combined modulation of local and systemic targets. One established target tissue is the airway mucosa where high local glucocorticosteroid concentrations ( $\left.\breve{S} 10^{-8} \mathrm{M},[2,15]\right)$ lead to a multifaceted, focal anti-inflammatory activity. A second target site, which apparently may be affected at low glucocorticosteroid levels $\left(ð 10^{-9} \mathrm{M}\right)$, could comprise production, maturation and disposition of key immune cells (e.g. eosinophils) in systemic compartments. The relative contributions of the different target sites are not well known. However, airway glucocorticosteroids lacking systemic effects, such as fluorcortin butyl ester, have exhibited poor clinical efficacy [17], suggesting that some concomitant systemic activity may, in fact, be a prerequisite for reaching the full antiasthmatic potential of inhaled glucocorticosteroids.

Nasal symptoms of seasonal allergic rhinitis were attenuated by inhaled budesonide in the present study. This partial efficacy, together with previous results demonstrating marked inhibition of nasal symptoms by nasally administered budesonide [18], suggests that orally inhaled budesonide cannot substitute for but could add to the nasal glucocorticosteroid treatment of allergic rhinitis. Corresponding effects of topical nasal glucocorticosteroids, i.e., beneficial effects on asthma, have already been observed in clinical studies $[4,5]$. Due to the high frequency of concomitant nasal disease in patients with asthma, the extrabronchial anti-inflammatory efficacy demonstrated in the present study may be considered, for the most part, as a desirable "systemic side effect".

Both circulating cells and the bone marrow, the latter as a stem-cell-producing organ, are potential targets for any systemically available budesonide in this study. Hence, glucocorticosteroid actions at these sites may have contributed to the reduced eosinophilia [19]. Local inhibition by budesonide of bronchial processes involving T-lymphocytes, eosinophils, and other cells may also have contributed to the present observations. One may speculate, therefore, that communications between the bronchial airways and the bone marrow (involving actions of cytokines such as IL-5 [20] and granulocyte macrophage colony stimulating factor (GM-CSF) [21], and chemokines such as eotaxin [22]), potentially promoting a "pan-airway" eosinophilia, could have been abrogated by the inhaled budesonide in this study. A combinatorial interplay of nasal and bronchial cells may also partly involve a nonselective airway migration of T-lymphocytes [23]. Hence, it cannot be excluded that steroid-sensitive leukocyte abnormalities occur in the entire airways in allergic conditions where the disease is largely confined only to the nose (or the bronchi). Irrespective of which targets and pathways are involved, the present treatment produced a marked effect, inhibiting 
the seasonal rise in blood and nasal eosinophils (and nasal lavage fluid levels of ECP).

Nasal lavage fluid levels of one of the largest plasma proteins, $\alpha_{2}$-macroglobulin (molecular weight $720 \mathrm{kDa}$ ), reflect the occurrence of microvascular-epithelial exudation of bulk plasma in human airways [6, 24]. The present study demonstrated an increased baseline exudation of plasma during the season and confirmed the graded exudation of plasma that occurs acutely in response to nasal challenges with histamine or allergen. When the nasal airway received a direct, topical treatment with glucocorticosteroids, the baseline exudation in allergic rhinitis was effectively inhibited [8]. In contrast, orally inhaled budesonide did not attenuate the nasal plasma exudation response in the present study. These data suggest that a significant local inflammation, even in the absence of increased eosinophilia, occurs in seasonal allergic rhinitis and that this inflammatory process is not inhibited by inhaled budesonide.

In conclusion, this study has demonstrated significant extra-bronchial anti-inflammatory effects of inhaled budesonide given at a dose of $600 \mu \mathrm{g}$ b.i.d. for several weeks during a birch pollen season and the seasonal rise in both circulating and nasal eosinophils was inhibited. This systemic and nasal anti-inflammatory efficacy was reflected further by a reduction in seasonal nasal symptoms. Nasal inflammatory processes were still present, as demonstrated by the baseline plasma exudation during the season, which was not attenuated by inhaled budesonide. If extrapolatable to asthma, the present data suggest that the inhaled glucocorticosteroids may have important antiinflammatory actions in the entire airways, including those sites in which the drug actually has not been deposited. The present systemic and nasal anti-eosinophilic activity may be a significant property of clinically efficacious glucocorticosteroids administered by inhalation, to the bronchial airways.

\section{References}

1. Barnes PJ, Pedersen S. Efficacy and safety of inhaled corticosteroids in asthma. Am Rev Respir Dis 1993; 148(4): S1-S26.

2. Linden M, Brattsand R. Effects of corticosteroid, budesonide, on alveolar macrophage and blood monocyte secretion of cytokines: Differential sensitivity of GMCSF, IL-1 $\beta$ and IL-6. Pulm Pharmacol 1994; 7: 43-47.

3. Henriksen JM, Wenzel A. Effect of intranasally administered corticosteroid (budesonide) on nasal obstruction, mouth breathing, and asthma. Am Rev Respir Dis 1984; 130: 1014-1018.

4. Reed CE, Marcoux JP, Welsh PW. Effects of topical nasal treatment on asthma symptoms. J Allergy Clin Immunol 1988; 81: 1042-1047.

5. Aubier M, Levy J, Clerici C, Neukirch F, Herman D. Different effects of nasal and bronchial glucocorticosteroid administration on bronchial hyperresponsiveness in patients with allergic rhinitis. Am Rev Respir Dis 1992; 146: 122-126.

6. Persson CGA, Svensson C, Greiff L, et al. Use of the nose to study the inflammatory response in the respiratory tract. Thorax 1992; 47: 993-1000.

7. Kapsali T, Horowitz E, Diemer F, Togias A. Rhinitis is ubiquitous in allergic asthmatics (abstract). J Allergy Clin Immunol 1997; 99: S138.
8. Svensson C, Klementsson H, Andersson M, Persson CGA, Alkner U, Pipkorn U. Glucocorticoid-induced attenuation of mucosal exudation of fibrinogen and bradykinins in seasonal allergic rhinitis. Allergy 1994; 49: 177-175.

9. Klementsson H, Svensson C, Andersson M, Venge P, Pipkorn U, Persson CGA. Eosinophils, secretory responsiveness and glucocorticoid-induced effects on the nasal mucosa during a weak pollen season. Clin Exp Allergy 1991; 21: 705-710.

10. Greiff L, Pipkorn U, Alkner U, Persson CGA. The "Nasal Pool-device" applies controlled concentrations of solutes on human nasal airway mucosa and samples its surface exudations/secretions. Clin Exp Allergy 1990; 20: 253-259.

11. Haldursdottir H, Greiff L, Wollmer P, et al. Effects of inhaled histamine, methacholine and capsaicin on sputum levels of $\alpha_{2}$-macroglobulin. Thorax 1997; 52: 964-968.

12. Lipworth BJ. Airway and systemic effects of inhaled corticosteroids in asthma: dose response relationship. Pulm Pharmacol 1996; 9: 19-27.

13. Lönnebo A, Grahnén A, Brundin RM, Ling-Andersson A, Eckernäs S-A. An assessment of the systemic activity of single and repeated doses of inhaled fluticasone propionate $(1000 \mu \mathrm{g}$ b.i.d. $)$ and budesonide $(800 \mu \mathrm{g}$ b.i.d. $)$ in healthy volunteers. Eur J Clin Pharmacol 1996; 49: 459-463.

14. Derom E, Van Schor J, Vinken W, Huybrechts H, Remgård P, Persson M, Pauwels R. A comparison of the systemic activity of two doses of inhaled fluticasone propionate and budesonide in asthmatic patients. Eur Respir J 1996; 9 (Suppl. 23): 162.

15. Edsbäcker S, Szefler S. Glucocorticoid pharmacokinetics: principles and clinical applications. In: Schleimer RP, Busse WW, O'Byrne PM, eds. Topical glucocorticoids in asthma: mechanisms and clinical actions. New York, Marcel Dekker. 1987; pp. 381-445.

16. Toogood JH, Frankish CW, Jennings BH, Baskerville JC, Borga O, Lefcoe NM, Johansson S-A. A study of the mechanism of the antiasthmatic action of inhaled budesonide. J Allergy Clin Immunol 1990; 85: 872-880.

17. Brattsand R, Axelsson BI. New inhaled steroids. In: PJ Barnes, ed. New drugs for asthma. London, IBC Technical Services. 1992; pp. 193-208.

18. Pipkorn U, Rundcrantz H. Budesonide and beclomethasone dipropionate in hay fever-a single blind comparison. Eur J Respir Dis 1982; 63 (Suppl. 122): 221-230.

19. Wooley MJ, Denburg JA, Ellis R, Dahlbäck M, O'Byrne P. Allergen-induced changes in bone marrow progenitors and airway responsiveness in dogs and the effect of inhaled budesonide on these parameters. Am J Respir Cell Mol Biol 1994; 11: 600-606.

20. Clutterbuck EJ, Hirst EM, Sanderson CJ. Human interleukin-5 (IL-5) regulates the production of eosinophils in human bone marrow cultures: comparison and interaction with IL-1, IL-3, IL-6, and GM-CSF. Blood 1989; 73: 1504-1512.

21. Denburg JA, Woolley MJ, Leber B, Linden M, O'Byrne P. Basophil and eosinophil differentiation in allergic reactions. J Allergy Clin Immunol 1994; 94: 1135-1141.

22. Griffiths-Johnson DA, Collins PD, Rossi AG, Jose PJ, Williams TJ. The chemokine, eotaxin, activates guineapig eosinophils in vitro and causes their accumulation into the lung in vivo. Biochem Biophys Res Commun 1993; 197: 1167-1172.

23. Wallaert B, Janin A, Lassalle P, et al. Airway-like inflammation of minor salivary gland in bronchial asthma. Am J Respir Crit Care Med 1994; 150: 802-809.

24. Svensson C, Andersson M, Greiff L, Alkner U, Persson CGA. Exudative hyperresponsiveness of the airway microcirculation in seasonal allergic rhinitis. Clin Exp Allergy 1995; 25: 942-950. 